\title{
“What I Call a Sound”: Anthony Braxton's Synaesthetic Ideal and Notations for Improvisers
}

\section{Graham Lock}

"See deeply enough, and you see musically."

"Tuned to its grandest level, music, like light, reminds us that everything that matters, even in this world, is reducible to spirit."

Al Young (132)

Flick through the pages of Anthony Braxton's Composition Notes and you'll soon encounter some striking visual imagery. In Composition \#32, for example, "Giant dark chords are stacked together in an abyss of darkness" (CN-B 375); Composition \#75 will take you "'from one room to the next'-as if in a hall of mirrors ('with lights in the mirrors')" (CN-D 118); in Composition \#77D slap tongue dynamics "can be viewed [as] sound 'sparks' that dance 'in the wind' of the music" (189); enter the "universe" of Composition \#101 and you'll discover "a field of tall long trees (of glass)" (CN-E 142). ${ }^{1}$ While it is not unusual for composers to employ visual images when discussing their work, Braxton's descriptions are clearly not illustrative in the sense of, say, Vivaldi's poems for La Quattro Stagioni or Ellington's droll explanations of his song titles. Rather than describe scenes that the music supposedly evokes, Braxton appears instead to offer extremely personal visualisations of the musical events and processes that are taking place in his compositions.

Further evidence of this highly individual perspective can be found throughout his work. Each of the five volumes of his Composition Notes begins with a list of "sound classifications": these are types of sounds that Braxton identified early in his career and compiled into a basic musical vocabulary. There are nearly 100 classifications, ranging from "curve sounds" to "gurgle sounds" to "petal sounds," and he gives each one its own visual designation. [FIGURE 1.] 


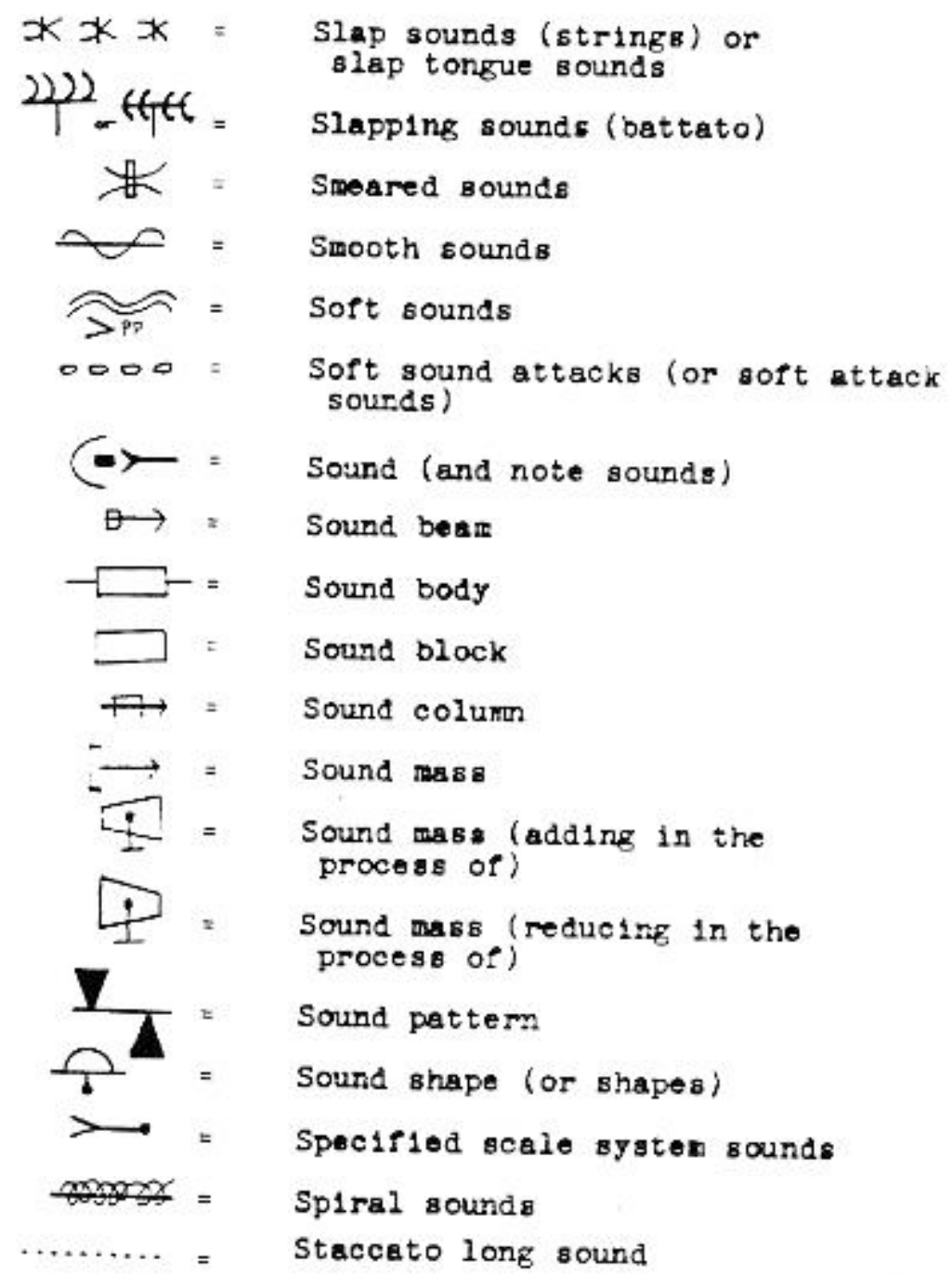

Figure 1. Examples of Sound Classifications listed in the Composition Notes. (C) Synthesis Music.

More eye-catching, and certainly more remarked upon, are his composition titles, also listed in the Composition Notes and, of course, reproduced on his CDs and LPs. Instead of using verbal titles, Braxton assigns each work a visual title: a diagram, comprising a mix of lines, shapes, colours, figures, numbers, and letters, which encodes both the structural and what he calls the "vibrational" elements of the music. ${ }^{2}$ [FIGURE 2.]
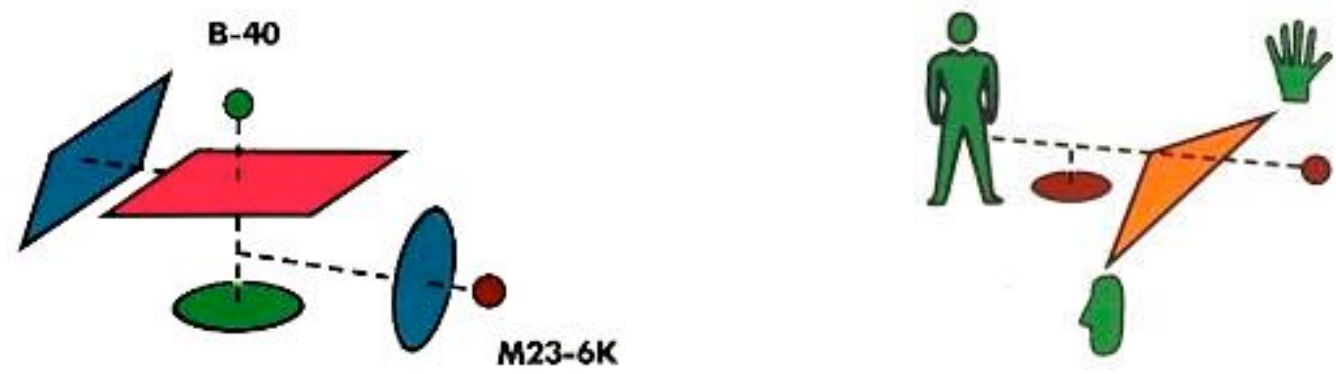

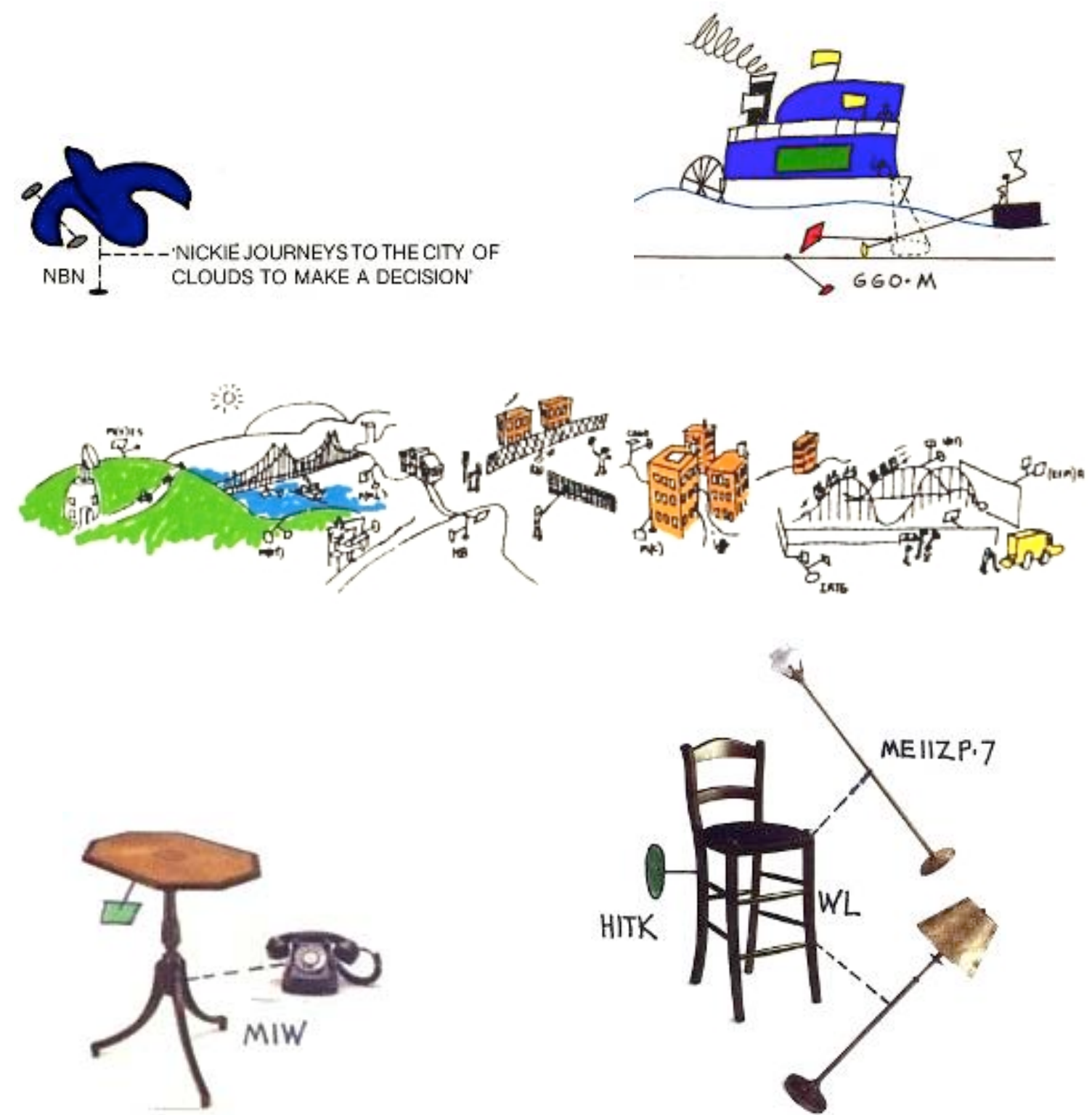

Figure 2. Examples of the composition diagram-titles, showing [top row] the use of colour and perspective (\#69Q, left), and figuration (\#105A, right), [second row] subtitles (\#110D, left) and a story image (\#122, right), [third row] landscape (\#142), and [bottom row] photo collages (\#184, left, and \#187, right). () Synthesis Music.

Add to these his frequent use of graphic and symbolic notations, his recollection that as a young man he would draw the solos of his favourite saxophonists, and his striking claim that he actually sees each of his compositions, "as if it were a three-dimensional painting" (Lock, Forces 99-102, 152), and it is clear that visual factors play a significant role in Anthony Braxton's conception of music.

My aim in this essay is to further explore this engagement with the visual, and in particular how it impinges on his compositional and performance practices via his creation of alternative notations. I have chosen to focus on a selection of these graphic scores for a number of reasons: one is that they represent the point at which visual elements impact most directly on the music; a second is that, compared to the much-discussed diagram titles, they have been rather overlooked; a third is that whereas Braxton has consistently refused to discuss the titles, saying they concern mystical areas that language is unable to address, his Composition Notes necessarily make reference to the alternative notations he uses, and so help to elucidate the role of the visual in his music. Braxton has also been willing to discuss at least some aspects of such scores in greater detail, and I will be including extracts from an interview I conducted with him in Brussels in February 2003. Finally, I want to consider, albeit briefly, whether these alternative notations, in drawing on such disparate sources as European Romantic mysticism and African American improvisational aesthetics, can be said to exemplify 
Braxton's statements that his music is "trans-idiomatic" and cannot be properly understood as belonging within either black or white cultural traditions.

"It is useful to consider the difference between music and the visual arts as a matter of degree, not of kind."

Simon Shaw-Miller (4)

First, a slight but necessary digression. Braxton's 1985 declaration, noted above, that he sees music "as if it were a three-dimensional painting" raises the possibility that he has a particular form of synaesthetic perception called chromaesthesia, or colour hearing, which would mean that he does literally see sounds as colours and shapes. The word "synaesthesia" is, according to consultant psychologist John Harrison, "a blend of the Greek words for 'sensation' (aisthesis) and 'together' or 'union' (syn), implying the experience of two, or more, sensations occurring together" (3). He adds that, in the majority of cases, the fusion comprises "a visual sensation caused by auditory stimulation"; this is chromaesthesia, in which a person sees colours and shapes when hearing a sound (3). (These associations are entirely involuntary; they cannot be evoked at will; they are experienced as normal—by which I mean as vividly real as any other sensory perception - by the synaesthete; and they remain consistent throughout a person's life.) I will say more about synaesthesia below, but first I want to record Braxton's own thoughts on the question, which I put to him in 2003, of whether the strong visual component in his musical thinking might be the result of chromaesthesia or some other kind of synaesthetic perception.

I don't really know. Your question is complex. There is a ring-post notch past which I don't try to analyse. But I would say this-there has never been an inherent separation in perception dynamics between the actual sound and the image internal reality connected to the sound, including colour, including vibrational spectra, i.e. radiance, timbre logics . . . I kind of see all of that as one thing.

I have never only heard a sound. If I hear a sound, I hear spectra . . . it's more threedimensional than the actual sound. I did not even realise that until I took ear training in college and I came to see that I wasn't exactly hearing what everyone else was hearing. For instance, I looked at some of the notated Warne Marsh solos and I was totally surprised to realise that, mechanically, some of the information looked very different to what I had been hearing.

I still feel that way. The attempts to notate the great solos from the masters of improvised music only capture maybe two-thirds of what actually happened in the music and that difference is part of what we're talking about. l'm thinking of the solo by Warne Marsh on "The Song Is You." I think as a young guy what fascinated me . . I I don't know how to say it ... Warne has a gravity and a vibrational presence that's ... It's like the notes are here [waves arm horizontally] but the real logic is in the internal world [waves arm at lower level]. I was more intrigued by that internal world than by the actual notes, in terms of how he was able to manipulate internal presence and feeling in his music. It's not something that can be written out. It was at that point that I would discover that what I call a sound is not necessarily what someone else would call a sound.

I think, for instance, that this concept of two-dimensional pitch in the Western music system is a form of reductionism compared to what is actually happening. And while I celebrate the invention of extended methodology and I bow to the great men and women who have evolved music science, at the same time many of the things that attracted me to music were threedimensional. The attempts to house it, to write it out, in many ways involved reducing the vibrational spectra of the music. I think the music we call jazz, so-called jazz, really brings it out, folk music brings it out, all of the musics that are close to the community and allow for individual presence bring out this dichotomy between the rational system and the threedimensional system. ${ }^{4}$

So the concept of image logics and the connection between acoustic actualisation and visual shapes and colours has to do with ... Well, this is what I was naturally hearing and sensing. Later, as I got older, I would find out that, whoever I am, I'm not actually sick or unhealthy because of the way I hear music. That, in fact, the more I would understand the wonder and dynamics of actualisation, the more I would find that in every culture there is a body of information that agrees, or is consistent, with what I'm saying. Which is not to say I'm right or wrong or anything like that; only that there is a continuum of information that has always emphasised three-dimensional presences, vibrational presences. (Braxton, Personal) 
I think it is fair to say that Braxton's experiences of sound, as described above, are certainly unusual and highly individualistic. But can they be interpreted as evidence of synaesthetic perception? The literature on synaesthesia seems to offer a few intriguing similarities. For example, while synaesthetic perceptions are classified as mental images, it is generally acknowledged that synaesthetes do literally see their images (called photisms) outside of their body, as if projected on a kind of visual field a little in front of the face-perhaps not unlike a three-dimensional painting appearing before your eyes.

According to Kevin T. Dann, synaesthetes "usually describe their photisms in geometric terms-'sparks,' 'spots,' 'lines,' 'streaks,' 'zigzags'” (72). He reports the case of two synaesthetes who "saw threedimensional geometric forms when they heard musical instruments played": the examples he lists include "seeing the flute as a thimble shape and as a hollow tube, a bugle as a sphere with an opening in its upper side, and the piano as quadrangular blocks and spheres" (72). It may be entirely coincidental, but many of Braxton's diagram titles, particularly from the 1970s and early 1980s, also resemble irregular three-dimensional geometric forms and shapes. ${ }^{5}$ [FIGURE 3.]
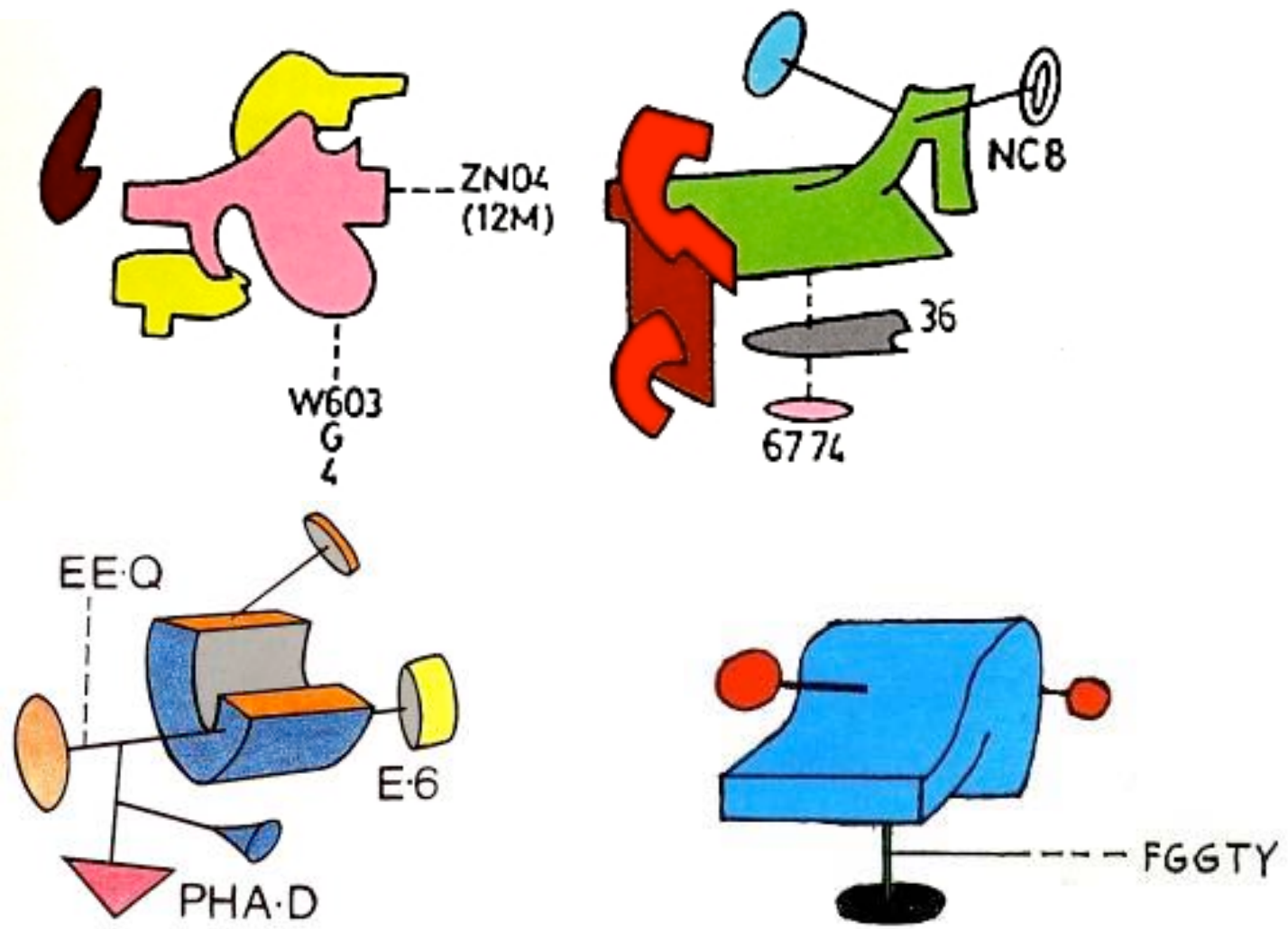

Figure 3. Examples of unusual geometric shapes in the composition diagram-titles. Top row: \#65, left; \#87, right; bottom row: \#96, left; \#101, right. (C) Synthesis Music.

Consider too Dann's description of synaesthesia as a "non-linguistic" experience, difficult to describe in words, which lends it a quality of "ineffability"; and his suggestion that synaesthesia is as much a conceptual process as it is a perceptual process, by which he means that synaesthetes not only see their perceptions but experience them as "a form of thinking," or what Dann also calls "felt meaning" (8n 81). ${ }^{6}$ Again, it is tempting to draw links between, for example, synaesthesia's "quality of ineffability" and Braxton's frequent criticisms of language as "mono dimensional"; or between Dann's notion of "felt meaning" and Braxton's experience, reported above, of "vibrational presence." Yet, while these resemblances are intriguing, they remain highly speculative-and, after all, musicians have long claimed that language is an inadequate vehicle for explaining and/or understanding their relationship to music. ${ }^{7}$ So the question of whether Braxton has synaesthetic perception is, as he says, complex and may be unanswerable. The problem is not simply that a music writer is hardly competent to judge, but that even those who have the requisite qualifications may not be able to agree. Despite more than a century of research, there is still no scientific consensus as to the exact nature and working of synaesthesia. ${ }^{8}$ One reason is that synaesthetic perceptions vary greatly from person to person and may be unique, at least in their specifics, to each individual. For example, while chromaesthesia may be the commonest form of synaesthetic perception, no two people with colour hearing will see the same shapes and colours even when listening to the same piece of music. A second reason is that, as mentioned above, synaesthetic experience is very difficult to communicate, so that those who have it find it almost impossible to describe and those who don't find it almost impossible to comprehend. 
Given that the issue of Braxton's supposed chromaesthetic perception appears to be unresolvable, I propose to broaden the terms of my inquiry and look instead at the notion that his music embodies and promotes what I will call a synaesthetic ideal, by which I mean an intellectual construct that has its own cultural history, which l'll outline in a moment. To put it simply, whether or not he literally sees sounds as colours and shapes, he certainly believes that they correspond on some levels and that such correspondences have both an aesthetic and a spiritual significance that he addresses in his music-as, for example, in his use of graphic and symbolic notations that attempt to circumvent the limitations of "two-dimensional" pitch. This is how Braxton explained it to me in 2003:

From the beginning, l've been interested in looking for the kind of connections that could make a given device holistic. By holistic here I mean with respect to mechanics, with respect to experience, and with respect to connections to other disciplines. In that context, you have sound, image logics (since we're talking about colour and painting) and dance. I think that, at the heart of what l'm trying to say, is that my interests and the work l've been pursuing are consistent with world culture. I'm not talking about something that has never been done before but rather something that we seem to have forgotten about that already exists.

I think that everything is connected and that the challenge of the next time period is not simply the advancement of a concept of entertainment or of music as separate from life, but rather the move towards three-dimensional, holistic experiences with music, image logics and dynamic spirituality all connected-including physicality, dance, movement. I'm looking for total integration. (Braxton, Personal)

Total integration of the arts, cultural synthesis, is part of what I mean by the synaesthetic ideal and Braxton is right to say this is nothing new. According to art historian Simon Shaw-Miller, "notions of media purity in modernism are the historical exception. The conception of fluid boundaries between the sonoric and the visual (and indeed also between the textual) is a closer reflection of artistic practices throughout history" (x). ${ }^{9}$ However, there is a particular mystical element to Braxton's thinking that we need to consider, not least because it crucially informs his views on music and the visual. This kind of mystical thinking is not new either: Braxton has often spoken of his interest in earlier cultures-which he sometimes calls "the ancients"-and has explained that this interest is related to that fact that many such cultures, from ancient Egypt and China to European Renaissance Hermeticism, have seen music as part of a network of mystical correspondences that includes not only colours and shapes but also astrological signs, numbers, times of the day, parts of the body, the elements, the seasons and the planets (Lock, Forces 294-307). Braxton has occasionally devised alternative notations that refer to these correspondences, as we will see in the case of Compositions \#76 and \#82; but before discussing specific scores, l'd like to try to locate these ancient beliefs in a more recent cultural context, which is also the point at which such networks first became conflated with synaesthetic art.

In his philosophical Tri-Axium Writings, Braxton argues that an awareness of mystical correspondences has long been the global norm and that all world musics have respected the notion of "vibrational presence." However, the despiritualisation of Western culture since the Enlightenment has, he says, resulted in Western classical music evolving separately from other world musics and developing according to what he terms "existential" criteria rather than with regard to spiritual values. This empiricism, which he links to the rise of materialism and mechanistic science, has, he claims, led to (among many other things) separation and specialisation, including the elevation of the composer over the performer and an emphasis on technique and "correct" playing at the expense of improvisation and personal expression. His own music represents an attempt to reverse these trends, or rather to balance them, not least because he sees the reunification of the arts as a requisite to the advent of a new spiritual awareness that will, he hopes, lead to global co-operation and peace (Lock, Forces 308-11).

Many of these ideas reiterate beliefs concerning art and spirituality that were integral to strands of European Romanticism in the late $19^{\text {th }}$ and early $20^{\text {th }}$ centuries: in the Theosophical writings of Madam Blavatsky, the Symbolist poetry of Rimbaud, the Expressionist paintings of Kandinsky, the musical experiments of composers such as Wagner, Scriabin and Schoenberg. The Wagnerian concept of the Gesamtkunstwerk (the total work of art); the quest for a universal language of colour, shape and sound; the belief in the synthesis of all art forms and in the transformational power of such a synthesis to usher in a new age of spirituality-all of these ideas, which were circulating in fin de siècle European salons, are echoed in Braxton's writings. Lest I be accused of imposing an unduly Eurocentric perspective here, let me stress that Braxton is certainly well-acquainted with this phase of European Romantic philosophy and has named several of its artistic progenitors—notably Wagner, Schoenberg and Kandinsky_among his major influences. (He has also spoken many times of his debt to Karlheinz Stockhausen, whose work can be seen as a later extension of the same mystical tradition.) ${ }^{10}$ 
In relation to the visual, Kandinsky has been of particular significance to Braxton. He has said that, of all painters, it is Kandinsky whose work most closely resembles the paintings he "sees" in his own music; he dedicated one of his earliest graphic scores, Composition \#10, to Kandinsky; and he has chosen Kandinsky paintings to accompany four of his recordings: Black Relationship, Looking Back on the Past, To Voice, and Blue Segment. ${ }^{11}$ The Belgian music writer Hugo DeCraen has enumerated many similarities between Kandinsky's work and Braxton's, with specific reference to the former's "experimental colour opera" The Yellow Sound and the latter's Trillium operas and series of theatrical "ritual and ceremonial" compositions. The two men, says DeCraen, share a fascination with colour/sound relationships as well as a belief that colour and sound each possess a spiritual quality or resonance that lends them a transcendental power (212-24). I would add that in Braxton's distinction between the "actual notes" and the "internal presence and feeling" of a Warne Marsh solo, we perhaps hear an echo of Kandinsky's belief that "a work of art consists of two elements, the inner and the outer," the inner being "the emotion of the artist's soul" (qtd. in Düchting 57).

Many people, then and now, have assumed that Kandinsky had chromaesthetic perception, although current scientific thinking suggests this was not the case. ${ }^{12}$ There is no doubt, however, that he was committed to affirming synaesthetic ideals in his painting and he played a leading role in the promulgation of these ideals in artistic circles, in part through his 1911 book Concerning the Spiritual in Art. Dann, in his study of synaesthesia as a cultural (as opposed to a neurological) phenomenon, notes that the first widespread scientific investigation of synaesthesia in the later $19^{\text {th }}$ century coincided with its appearance as an artistic ideal in the salons of the avant-garde (13). He also argues that it was at this time, chiefly through popular misconception, that synaesthesia was first-and, he insists, erroneouslylinked with the mystical correspondences found in earlier cultures, a linking that transformed it from, in Dann's words, "a perceptual idiosyncrasy" into a "particularly attractive symbol for disaffected moderns looking for signs that unity might be recovered" (37-42). ${ }^{13}$

Once conflated with the astral and the occult, synaesthesia was acclaimed by many artists as a form of superior spiritual insight and work based on synaesthetic principles became fashionable. Such views were far from unanimous, however: cultural conservatives denounced synaesthetic art as decadent, while scientific positivists regarded synaesthesia itself as a type of mental illness. One result of the ensuing controversy was that synaesthetic beliefs became sufficiently well-known to attract the barbs of literary satire. In James Huneker's 1902 story "The Disenchanted Symphony," the protagonist Pobloff is a composer/conductor who deems colour hearing an advanced form of artistic perception and believes in the mystical power of music. During a rehearsal of his "experimental" symphonic poem, "The Abysm," Pobloff is aghast to see his orchestra suddenly vanish "into a darkness that freezes the eyeballs" and realises that the mystical forces unleashed by his music have transported the musicians into the fourth dimension (332-33). Frantic, he eventually manages to bring them back by performing "The Abysm" backwards on the organ! ${ }^{14}$ I'm not aware of Braxton's music ever dispatching the musicians into a different dimension (although some of his scores do include the option of performing the notation backwards), but given his familiarity with the same European mystical beliefs that Huneker was satirising, we should not be surprised that Pobloff's thinking, and even his terminology, can seem on occasion to anticipate Braxton's own:

Why should the highly organised brain of a musician be considered abnormal because it could see tone, hear colour, and out of a mixture of sound and silence, fashion images of awe and sweetness for a wondering, unbelieving world? If Man is a being afloat in a sea of vibrations, as Maurice de Fleury wrote, then any or all vibrations are possible. Why not a synthesis? ${ }^{15}(329)$

What I want to suggest, then, is that in the synaesthetic ideals espoused by fin de siècle artists such as Kandinsky, Braxton found an inspiration for, or at least an affirmation of, the synaesthetic ideals he was exploring in his music. (And, possibly, he also found a context in which to make sense of his personal auditory perceptions, a reassurance that he was "not actually sick or unhealthy because of the way I hear music," a perceptual experience that, after all, neither scientific research nor the English language has been able to describe or explain satisfactorily.) Here was an influential artistic movement that provided a framework both for a synaesthetic aesthetic and for the mystical correspondences that derived from the ancients. Yet we should be cautious about situating Braxton's spiritual beliefs solely in this, or any one, context. In his early years in the AACM, he researched music's relationship to mysticism in a number of cultures, and his writings confirm that he is familiar with many different spiritual traditions. ${ }^{16}$ There is, of course, a profound and long-standing African American mystical tradition, which, as outlined by Grey Gundaker, includes a variety of alternatives to "mono dimensional" language, such as personal codes, graphic scripts and spirit writing. While it may be possible to align some aspects of Braxton's work with this tradition, I believe that to do so risks a kind of racial reductiveness, not least because Braxton himself has rarely mentioned such sources, whereas he has spoken frequently of his admiration for the work of Kandinsky, Wagner, Schoenberg and Stockhausen, and claimed an affinity with its spiritual content. 
But even if I am right in nominating European Romanticism as a major influence in reference to the visual-cum-mystical areas in his music, it remains to be seen how he actually employs these factors in his compositional and performance practices-and it is at this point, I think, that the African American creative music tradition plays a crucial role. This is the issue I will address in the next part of the essay. As a preparatory step, let me stress that the conjunction of such apparently disparate influences is in accord with Braxton's contention that his music is "trans-idiomatic," that it cannot be categorised as being either predominantly European-influenced or predominantly within a jazz/black music tradition. By tracing the relationship between his mystical beliefs and his music making, and in particular by examining how visual factors work in relation to his uses of notation and improvisation, my hope is that we can also reach a better understanding of the term "trans-idiomatic" and how it operates in Braxton's oeuvre.

"Hear with your eyes, see with your ears."

Charlie Parker (qtd. in Taylor 248)

In the Tri-Axium Writings, Braxton argues that notation plays a different role in Western classical music than it does in African American creative music, where improvisation on written material is more highly prized than the correct execution of it:

Notation as practised in black improvised creativity is not viewed as a factor that only involves the duplication of a given piece of music [. . .] Rather this consideration [i.e. notation] has been used as both a recall factor as well as a generating factor to establish improvisational coordinates[. . . ] Notation in this context invariably becomes a stabilising factor that functions with the total scheme of the music rather than a dominant factor at the expense of the music. ( $T-A W$ $335-36)^{17}$

In many black musics, Braxton is saying notation is used as a guide or platform for improvisation-for example, in the way a written-out ensemble riff might underpin an improvised solo-so that the score is only one component of the total performance, whereas in the Western classical tradition there is generally more emphasis on a faithful rendition of the score as being the main focus and purpose of the performance. This insistence on interpretative accuracy, and the "correct" technique it requires, though adopted by many jazz critics, is, says Braxton, foreign to the African American understanding of improvisation as a "vibrational continuum that differs from moment to moment / person to person" $(243):^{18}$

The fact is, improvisation as practised in the working arena of black creativity is related to many other factors that are outside the actual 'doing' in the music. I am writing of a functional idea that utilizes both a fixed and open operational scheme-whose ultimate significance has nothing to do with the execution of its co-ordinates but is instead concerned with how a given participation is able vibrationally to affirm what is being dealt with. (248)

These ideas cast light on Braxton's 2003 comments about the necessity of allowing "vibrational spectra" and "individual presence" into the music. And it is not hard to see how graphic and symbolic notations could facilitate these processes: they operate as improvisational portals through which vibrational factors such as personal creativity and "the feeling of the moment" can infuse a performance, thereby ensuring that the score retains the potential to be relevant to any player (and any community) at any time. While Braxton adheres to the same values in regards to his conventionally notated works, ${ }^{19}$ in which he also encourages players to improvise in a variety of different ways, ${ }^{20}$ graphic scores allow wider scope for improvisation and have the advantage of undermining critical notions of "correctness," since there is no correct way to play, say, a sequence of coloured shapes. They can also encourage players to explore the full potential of their instruments, going beyond normally prescribed (because conventionally notated) parameters, so creating a personal sound/style that will better express "individual presence," or what Braxton also calls "the whole of their 'life' position," and which he considers an absolutely vital element of performance (249-50). ${ }^{21}$ When we turn to the Composition Notes in a moment, we will see that Braxton's comments therein make clear that his own work is conceived largely (though certainly not exclusively) in accord with the precepts of "black improvised creativity" that he outlines in the Tri-Axium Writings, particularly in regard to the central role of improvisation in musical performance and the use of notation, not least his synaesthetically inspired alternative notations, "as a generating factor to establish improvisational co-ordinates" (35).

Let's now look at some examples of Braxton's graphic and symbolic scores; and so that readers may, if they wish, listen to the music under discussion, I will try to restrict myself, as far as is possible, to works 
that have been released on disc. The first work described in the Composition Notes is Piano Piece 1, aka Composition \#1, written in $1968 .{ }^{22}$ Braxton spells out that the composition "contains many of the ingredients that would come to preoccupy my attention in creative music," one of the more crucial being "the interrelationship between functional tenets and individual expression" (CN-A 1). This relationship is reflected in the score's mixture of what Braxton calls here "visual" and conventional notations. ${ }^{23}$ The former, he says, is intended to promote improvisation and derives from his "desire to encourage more involvement" from the instrumentalist, as well as to explore the dynamic "between fixed and open structures" (6). As a result, a performance of the work "is an affirmation of myself as a composer as well as [of] the interpreter-as a creative person in his or her own right" (6).

Already we see here several of the key components in Braxton's musical thinking. The "affirmation" of the performer is a recurring theme that runs throughout the Composition Notes (and is a means of enabling "individual presence"), as is the use of various types of "visual" notation to promote the improvisation that allows this affirmation to occur. Other salient points, such as the focus on the relationship between structural elements ("functional tenets") and personal expression, and the use of both alternative and conventional notations to mediate this relationship, also recur throughout the Composition Notes. ${ }^{24}$

Braxton employs various alternative notations in several of his earlier compositions, usually in conjunction with conventional notation, although occasionally a score is entirely graphic. In Composition \#10, for example, originally for solo piano and dedicated to Kandinsky, the score comprises sixty-eight visual figures, created from combinations of seven basic shapes that are linked to the seven basic musical components of the composition. ${ }^{25}$ Initially the figures were grouped together four per page [FIGURE 4.],

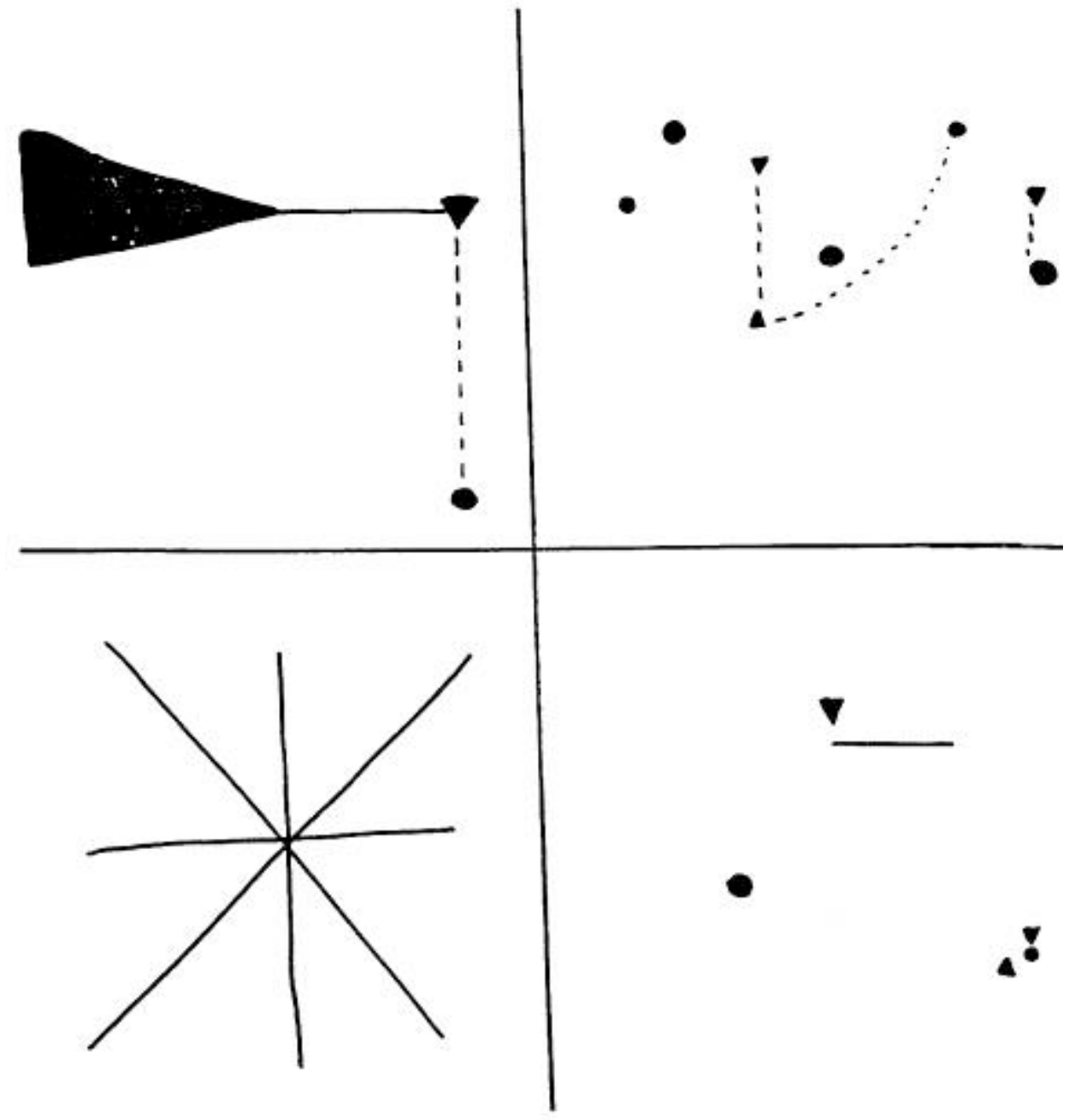

Figure 4. Figures from the original graphic score of Composition \#10. @ Synthesis Music.

but when Braxton revised the score in 1982 he transferred them to individual cards. Register, dynamic and pitch choices are left open to the performer, as is the duration of the piece and the order in which 
the figures are played. Yet this is not free improvisation: each shape corresponds to a particular type of sound, specified by the composer (these include trills, clusters, rumbles and pedal sounds), and the player is asked to respect both these associations and the relationships between the shapes in each figure. In his notes, Braxton explains that he had two major goals with this work: firstly to help "restore our awareness of composite cultural dynamics" (that is, \#10 aspires to the synaesthetic ideal that he sees in earlier cultures) $(174) ;{ }^{26}$ and then, again, to encourage the complete participation of the performer. The visual figures, he says, offer the player "a basis for self-examination and discovery," such activities being, he adds, "important to our growth as creative musicians" (181).

The intention to reaffirm "composite cultural dynamics" features more prominently in works where Braxton makes direct reference to the correspondences found in earlier mystical traditions. In Composition \#76, for example, he links the colour notation to astrological signs (while in Composition \#82 he relates the colours in the score to both their astrological and numerological equivalents). ${ }^{27}$ Braxton has explained how the correspondences work in Composition \#76: according to astrological tradition, each sign is associated with both a colour and a set of emotional characteristics-Taurus, for example, is linked with green and with feelings of calm and restraint; Aries is linked with red and with intense, explosive emotions. So, in the score of \#76, the colours signal those emotional correspondences: green indicates play calmly, red indicates play with intensity, etc. Shades of colour mark factors such as dynamic and tempo: the darker the hue, the faster and/or louder you play. ${ }^{28}$ [FIGURE 5.]

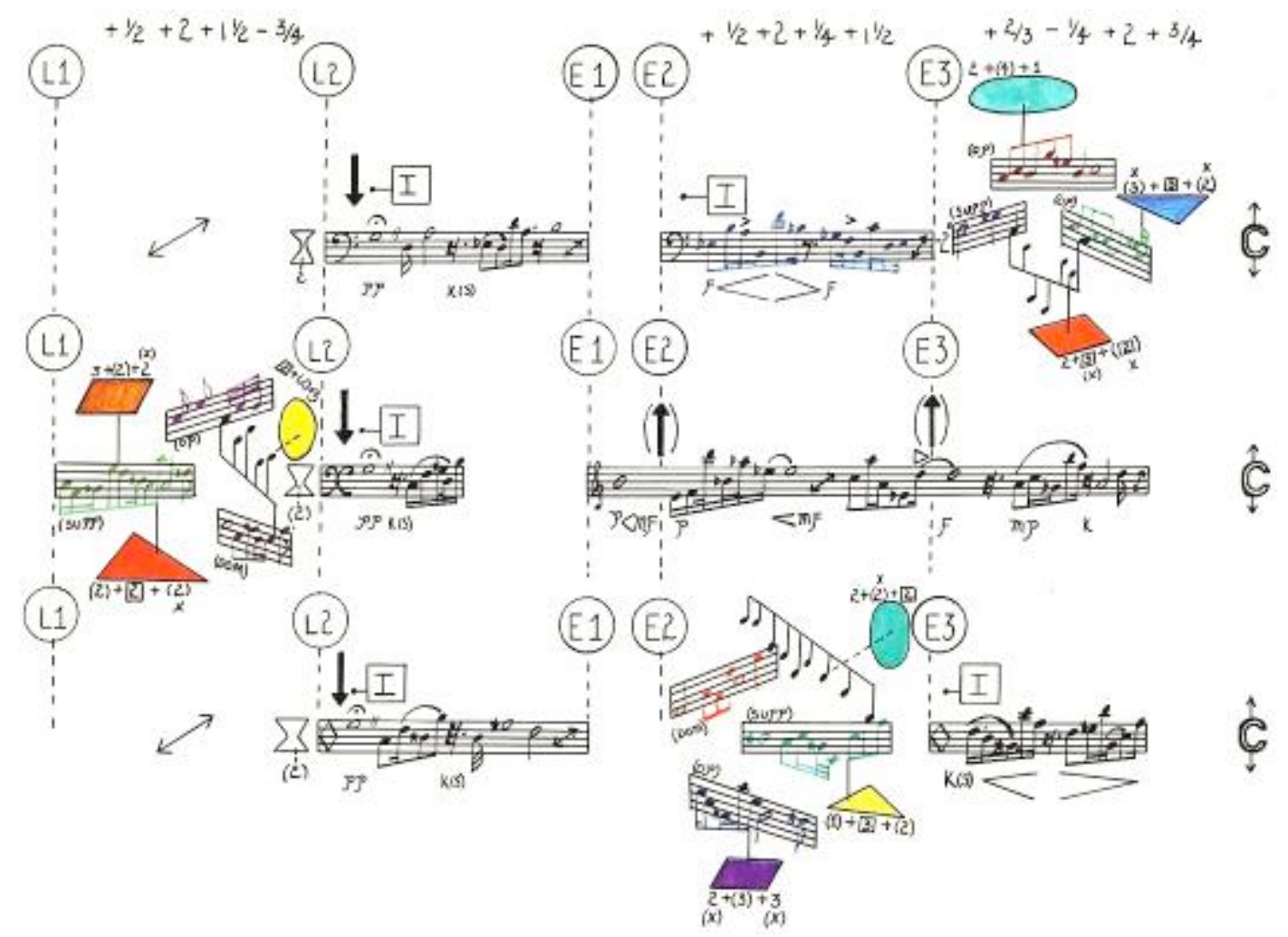

Figure 5. Examples of the colour and shape notation used in \#76. In this example the shapes indicate different kinds of improvisation, the numbers adjacent to the shapes refer to phrasegroupings and the " $x$ " symbol offers the performers the option of singing instead of playing. Brackets signal "change instruments" (\#76 is written for three multi-instrumentalists). (C) Synthesis Music.

Composition \#76, written in 1977, heralded a new phase in Braxton's music that saw even greater emphasis on the use of "visual" notations. Compositions \#78, \#84 and \#90, for instance, are almost entirely graphic scores: \#78 is a "workshop forum," the chief purpose of which is to encourage players to familiarise themselves with the use of shapes and colours as guides for improvisation; \#84, dedicated to Picasso, comprises nine given shapes arranged in various configurations. [FIGURE 6.] 


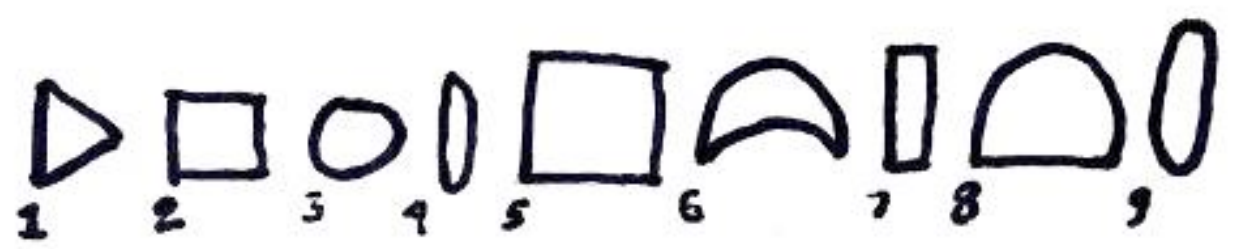

Figure 6. The nine shapes used in "visual notation" for \#84. ㄷ Synthesis Music.

Each shape relates to a maximum of four sound-types, chosen by the players from a list of twenty options given in the score. ${ }^{29}$ As Mike Heffley has noted, Braxton's urging of the performers to make their own selection of sound/shape correspondences suggests that "he's trying to provoke in the players their own experience of such visual-audio connection and creativity-even a mystical experience-rather than imposing his own on them" (394). This further concentration on the visual reflected, in part, Braxton's developing interest in the visual elements of performance itself-lighting, costume, set design, choreography-as he embarked upon his series of highly theatrical "ritual and ceremonial" works, beginning with Compositions \#95, \#96, \#102 and \#103, which also brought increasingly explicit use of mystical associations and aims. (Composition \#95, for instance, composed as "a vehicle to alert the spirit about serious change," employs both colour and numerological correspondences in the score. $)^{30}$ And even in contemporaneous non-ritual works, such as Compositions \#94, \#98, \#100 and \#107, there's a renewed emphasis on extending the visual parameters of the score to include shapes, symbols and what Braxton calls "multiple notation."

Composition \#94, for three instrumentalists, features several different kinds of alternative notations that provide what Braxton describes as "a dynamic context for creative exploration and visual integration" (CN-D 471). ${ }^{31}$ Section A's "symbolic notation," for example, draws both from the list of "sound classifications" in the Composition Notes (the players pre-select twenty of these to insert into the score) and from a set of ten geometric shapes that are specific to \#94. These two sets of symbols function, says Braxton, as a "language texture-or fabric (in the same sense as vertical harmonic directives but from a more subjective basis)" (462); by which I assume he means that the players can improvise on a sequence of shapes and symbols much as they would on a series of chord changes, the main difference being that the former offers a greater degree of interpretative flexibility. This flexibility remains circumscribed, however, because each shape targets certain conceptual and/or psychological areas for the players to explore, while leaving pitch choices, etc. open to the individual.

Section B's "image grouping notation" is even more intriguing, not least because it reappears in several later compositions. Braxton lists three sub-categories of this notation: "liquid formations," "shape formations," and "rigid formations." Liquid formations occur when the cloud-like figures intertwine with conventionally notated pitches: the players are asked to "blur" those notes that fall within the shape and create "clouded mass sound imprints that form a multiphonic and 'transformed' state of sound" (467). [FIGURE 7.]

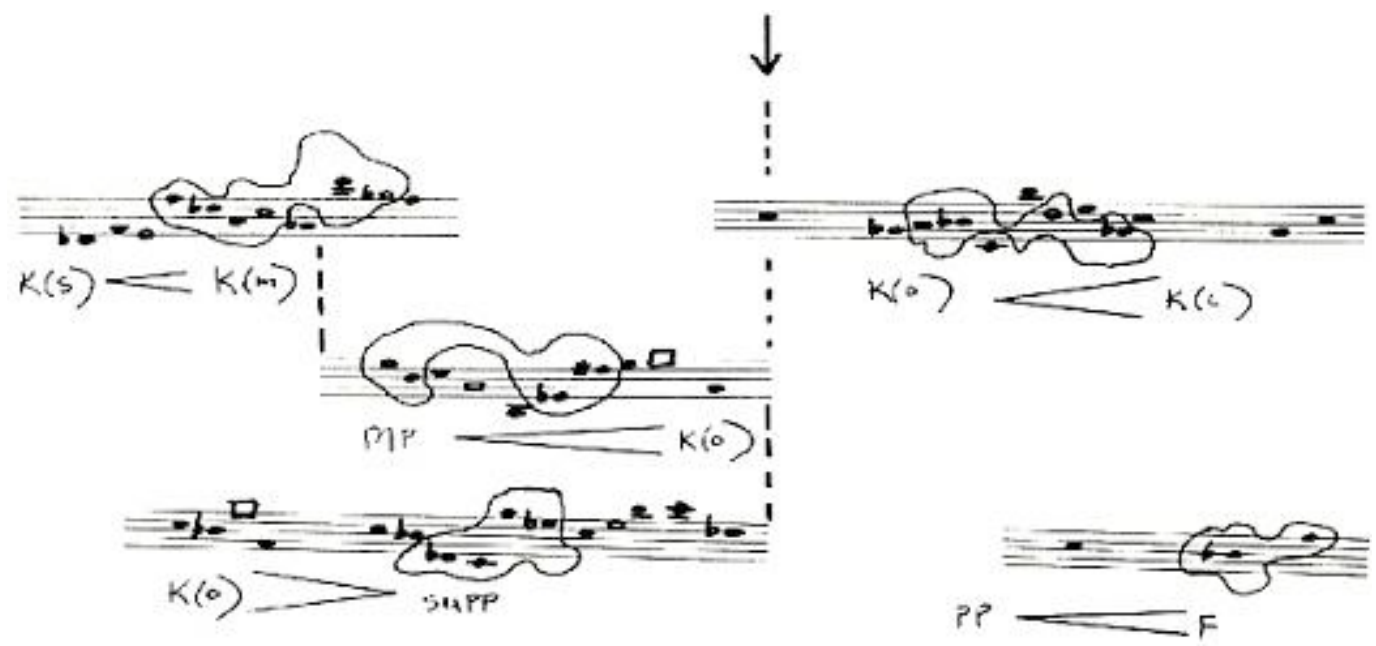

Figure 7. Examples of "liquid formations" from the score of \#94. ㄷ Synthesis Music. 
(The players have the option of tracing either the upper or lower outline of the shape, or both, or a combination of the two.) "The challenge of this context," Braxton avers, "is to breathe a music whose contours respect the line flow of the shape but whose effect statement affirms the personality of the interpreter" (469). ${ }^{32}$ Shape formations are similar to liquid formations, except that the players are asked to give the shapes "harder edges," while rigid formations extend this hardening process to "emphasize the composite state of a shape's formation" (471). ${ }^{33}$ [FIGURES 8 and 9]

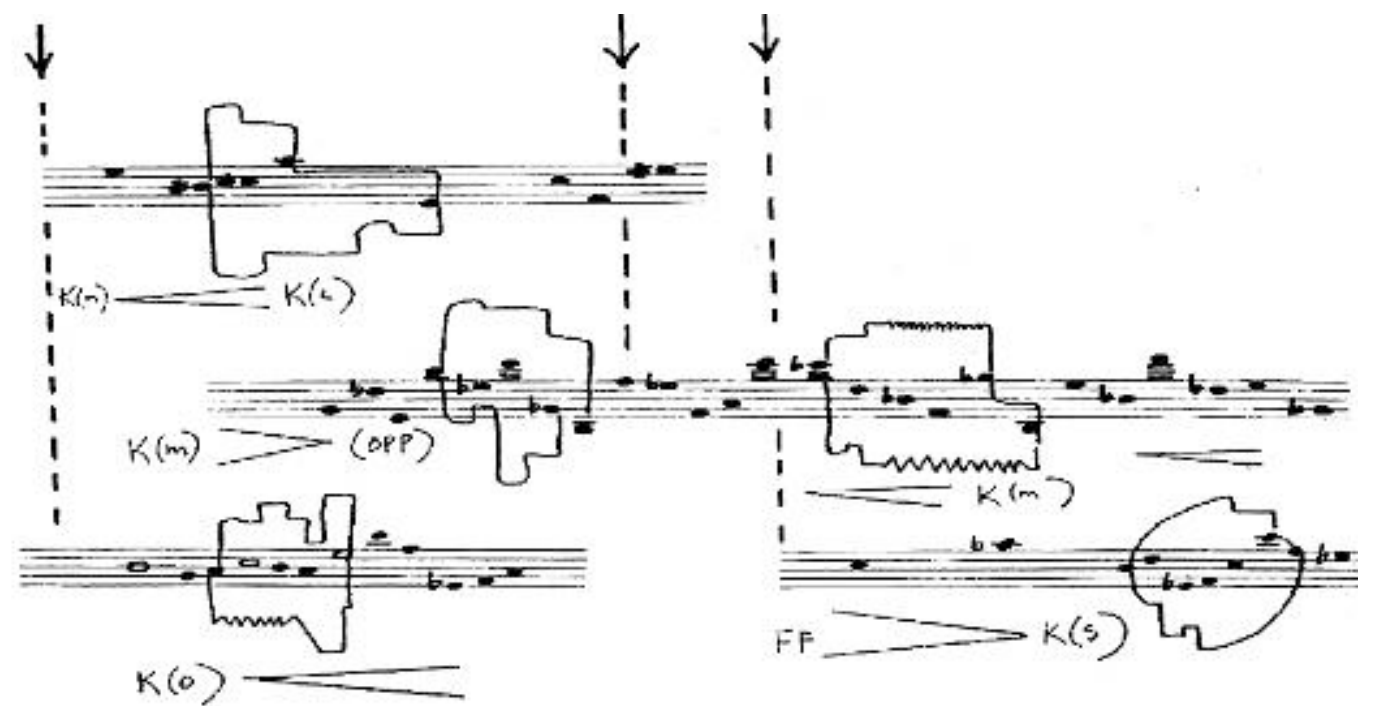

Figure 8. Examples of "shape formations" from the score of \#94. CSynthesis Music.

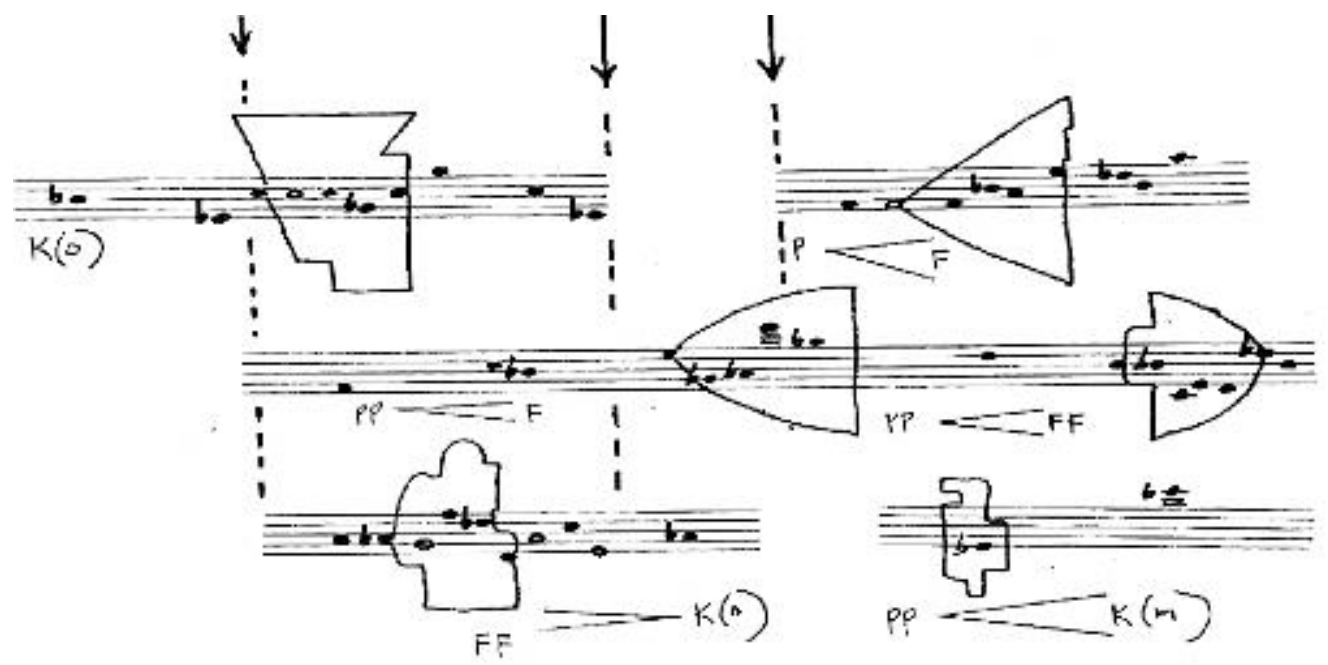

Figure 9. Examples of "rigid formations" from the score of \#94. (Synthesis Music.

Although Braxton's music has rarely observed the customary divisions between composition and improvisation, this "image grouping notation"-and similar shapes recur in the scores to Compositions \#98, \#100 and \#107-collapses the distinction even further. In his notes to Composition \#98, he writes that the work is neither "notated [n]or open but rather a 'bridge' between both disciplines" (CN-E 87). ${ }^{34}$ More recently he has referred to his scores from this period as marking "the beginning of an improviser's notation":

I was seeking to establish models of notation that a) would be open to the new multiinstrumentalism that had been developed in the AACM; b) would allow the instrumentalists more flexibility as well as challenge them to stretch their vocabularies; and c) could define 
particular conceptual, psychological and correspondence spaces for extended improvisation (qtd. in Lock, "Hearing" 3).

These comments point to the innovatory implications of Braxton's alternative notations. It's not only that he is using these visual elements to urge players towards new areas of personal expression; he is also using them to integrate composition and improvisation in new ways and to radically revise notions of form. So, whereas traditional Western classical form tends to be closed to improvisation and traditional jazz form is open chiefly to what he calls "the separate brilliance" of the extended improvised solo ( $C N-E$ 83), works such as Compositions \#94 and \#98 represent a kind of porous or non-finished form in which tiny pockets of improvisational space permeate the musical structure. ${ }^{35}$ This embedding of space within the formal fabric of the composition, via the visual "improviser's notation," means it is virtually impossible to play these works, even as a straight run-through of the score, without "individual presence" and the "feeling of the moment" suffusing the performance. ${ }^{36}$ Such non-finished forms present individual improvisers with a fresh kind of challenge (there are no extended solos) and also call for fresh kinds of ensemble interplay: here the synaesthetic ideal has led to a music that is "trans-idiomatic," not only because it synthesizes disparate influences, but especially because it proposes new kinds of formal logic. $^{37}$

In Composition \#96, Braxton's synaesthetic ideal prompts another radical experiment with visual stimuli for improvisation. Written for orchestra and four slide projectors, the work comprises an orchestral score, in conventional notation, and a photographic score, based on twelve religious symbols from ancient cultures, including Celt, Christian, Egyptian, Greek, Hebrew, Mycean and Native American. [FIGURE 10.]

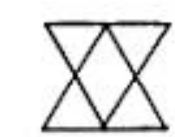

Two triangles

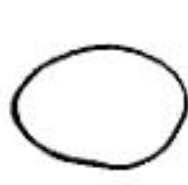

Ezrptian sign of the seasons

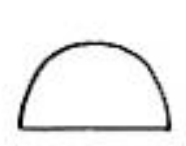

Egyptian mystery sign Egyptian mystery rign

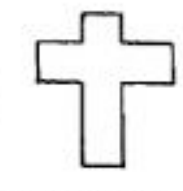

Christian Cross
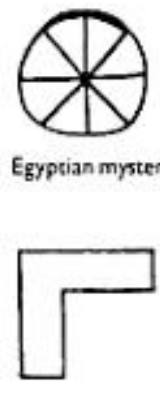

Egyptian sign of the Zodiac representing truch, justice and law

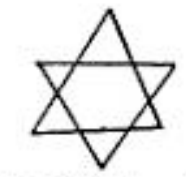

Scar of David

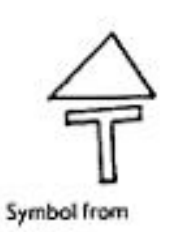

Mexico

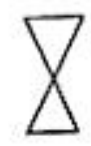

Central and South American Indians

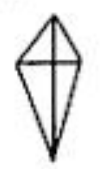

Symbol of the North and South Pole

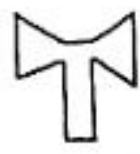

The Mycenaean Trce and Pillar Cult

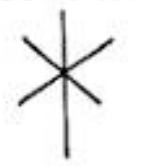

Horus I or Amsu (the risen Horus)

Figure 10. The twelve religious symbols that comprise the photographer's "score" in \#96. CSynthesis Music.

The photographer is invited to seek out and shoot examples of these symbols in the natural world- "to find the Star of David in a snowflake or in a texture of trees-or in a reflection in the water"-and the resulting slides are then synchronised with the musical score in performance $(C N-E 46) .{ }^{38}$ Braxton's mystical beliefs inform the entire work, which, he says, is "an affirmation of its numerological equivalent-the number seven" (so it comprises seven parts, divided into sixteen segments, and employs sixteen different "language strategies" and sixteen different visual images: in numerology $16=$ $1+6=7$ ), and is designed "to celebrate the composite interrelationship between dynamic symbolism and world change" ( $C N-E 26)$. This mystical intent clearly lay behind the conception of the purely visual photographic score, yet it's worth noting that Braxton employs the score in much the same way as he uses his graphic music scores: that is, he encourages the photographer to "improvise," to create his or her own images in response to the symbols, just as he encourages the musicians to improvise on the colours and shapes of his alternative notations. Ensuring the "individual presence" of the participants remains a top priority.

To conclude, l'd like to look briefly at one final example of Braxton's "notation for improvisers," not least because we have a detailed account of how it worked in performance. Composition \#108B was composed in 1984. It is one of a set of four "pulse tracks," a term Braxton devised for pieces he created specifically to be played concurrently with other compositions (a notion that was, in turn, linked to the idea of "collage forms," which he began to explore in the early 1980s). ${ }^{39}$ The way this worked in his quartet, which was the context in which he initially developed pulse tracks, was that normally the bassist and percussionist would play the pulse track, while the other two quartet members played or improvised 
on other notated material. Three of these early pulse tracks—Compositions \#108A, \#108C and \#108Dare written in conventional notation, but Composition \#108B is a graphic score that consists entirely of curvy lines and dots, while numbers across the top indicate beats per section. [FIGURE 11.]
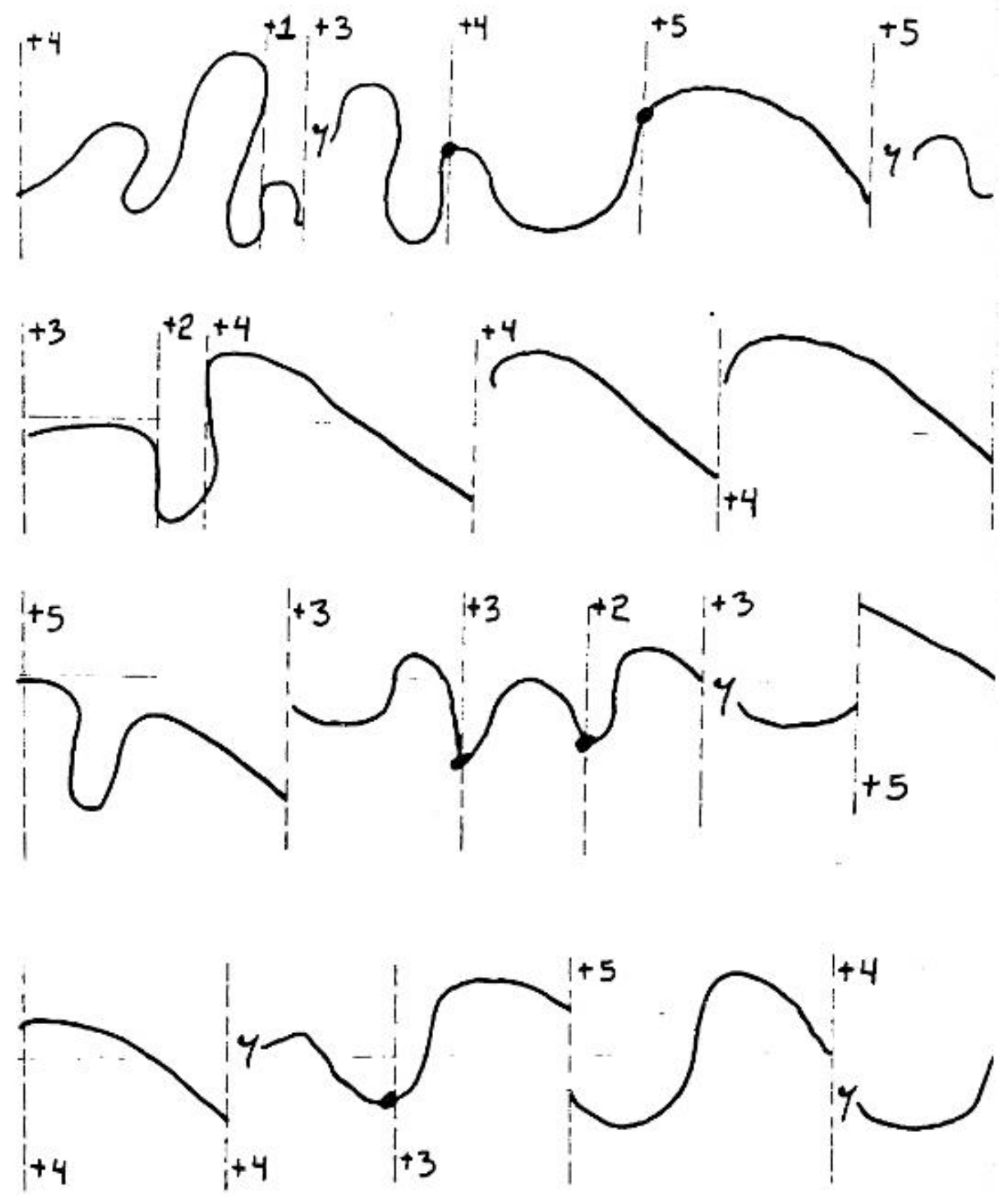

Figure 11. An example of the graphic score for \#108B. CSynthesis Music.

Braxton describes \#108B as "a series of possible curve line sounds or curve line dynamic changes" (311), implying that the lines can indicate pitch and/or volume, and he likens the music first to "a continuum of stresses and 'whispers' (as if a gust of wind has rushed through the sound space of the music and stirred up the mix of its ingredients)" (314), and later to "a 'sea' of ocean waves that contains a continuum of rising and falling vibrational (and actual) dynamics" (316). ${ }^{40}$ The intention behind the work, as in earlier examples, is both to implement the synaesthetic ideal ("to help in the cause of world unification and spiritual growth") and to extend the improvisatory possibilities of the creative music tradition (to enable the players to "seek out a new world and feelings (positive feelings)") (CN-E 317). Fortunately, we're able to glean some insight into how these intentions, and the graphic notation, translated into performance practice because we have a description by Gerry Hemingway, percussionist 
in Braxton's quartet from the early 1980s to the early 1990s, of how he approached the score in concert, initially in conjunction with bassist John Lindberg, then later with his successor in the quartet, Mark Dresser. $^{41}$

$108 \mathrm{~B}[. .$.$] is nothing but numbers and lines that go up and down, with wavy motions to them$ that suggest glissandos, dynamics, but could be anything-Anthony didn't specify, he allowed us to make our interpretations of what the shapes are. They're interesting in that they do hold you together, though Mark and I, as well as John Lindberg and I, developed various ways of interpreting the score.

John Lindberg and I tended to lean towards glissando. We would follow the shapes fairly literally and we'd try to adhere to the time lapses that were happening. We'd be deliberate, but not too much, so we'd stretch them out and open them up in certain ways. More recently, Mark and I do a number of other things within the diagram system. Sometimes I use it as a velocity diagram, so as the line goes up I increase the velocity of whatever I'm doing: sometimes it gets faster, sometimes faster and louder, speed and dynamics. Or l'll do inverse things, so when the line goes up, I slow down. I try to keep changing the relationship.

The other thing is that these dots also keep appearing in the score. We usually hit them, but sometimes we mime them, just to keep ourselves connected. I use them sometimes as accents; other times I use the dots as points of change-where l'm doing one sound that leads down to the dot [. . .] then, from the dot, l'll change to a whole other texture, or from glissando to velocity. Mark and I have actually gone further with this and figured out more things to do, but it's very open-ended, you can do a lot with it. The kick of it is we're usually figuring out how to do these things right on stage. We talked about it when we first played it, but since then we don't articulate to each other directly, we're doing it right there in the moment, being quick with each other, each understanding what the other is doing (qtd. in Lock, Forces 261-62). ${ }^{42}$

Hemingway's account is, I think, eloquent testimony to the efficacy of Braxton's alternative notation, at least in Composition \#108B. It did spur the musicians to explore fresh kinds of improvisation and interplay, and-while retaining certain "functional tenets," such as keeping them connected-it also offered the players extensive scope for individual expression (and by means other than the extended solo). It is rather more difficult to gauge how well \#108B has fulfilled Braxton's aim of promoting "world unification and spiritual growth," though the fact that it prompted its performers to improvise new ways of working together can perhaps be seen as a small step along that road.

"Mystery is a necessary part of process."

Karlheinz Stockhausen (103)

The five volumes of Composition Notes that Braxton has published to date cover the years 1968 to 1986, and the last work he discusses in detail is Composition \#116. Nevertheless, later CD notes and interviews suggest he has continued to both use a variety of graphic and symbolic notations and to pursue the twin goals of promoting the synaesthetic ideal and of affirming a greater degree of "individual presence" for the performers. The latest phase of his work, which he calls "Falling River Musics," may be the most reliant to date on visual stimuli, and will, he says, "seek to explore image logic construct 'paintings' as the score's extract music notation" (qtd. in Wilmoth). Charlie Wilmoth, who has seen these new graphic scores, describes them as "large, colorful drawings (reminiscent of the titles of Braxton's earlier compositions) alongside much smaller writings that initially look like doodling" (Wilmoth). These smaller writings, he adds,

are accompanied by an intentionally vague legend that begins near the top of the page with a quarter note. Subsequent drawings in the legend look less and less like musical notation, and they quickly become unrecognizable as such. Braxton refuses to assign any specific meanings to the notations of his Falling River scores, since part of their purpose is to allow each performer to find her own way through them. (Wilmoth)

He goes on to quote Braxton's explanation that "I am particularly interested in this direction as a means to balance the demands of traditional notation interpretation and esoteric inter-targeting" (Wilmoth).

The key word here is balance. Braxton's alternative notations are (and always have been) meant to complement, not to replace, conventional notation, because he believes that no one type of notation, no single method of improvisation, can encompass all the possibilities that music has to offer. This inclusive aesthetic is part of the synaesthetic ideal, and works such as Compositions \#94, \#98 and \#108B remind 
us that this ideal is implicit in Braxton's music, even when the specifics of the visual notation-the actual shapes and symbols and colours-do not come freighted with astrological, numerological or other mystical associations. The images act as improvisatory portals through which "individual presence," with all its mystery and unpredictability, can enter into the process of performance. And the synaesthetic ideal is always present, both in the bringing together of the visual and the musical, and in the broader impulse for cultural synthesis that underpins nearly all of his work, even when he employs only conventional notation.

Braxton's description of his work as "trans-idiomatic" is perhaps best understood as part of this same belief in embracing unity. ${ }^{43}$ His music mixes European Romantic mysticism and African American creative music aesthetics, notation and improvisation, jazz and classical—and innumerable other Others - without being circumscribed by any of the boundaries that conventional wisdom has placed around these idioms. ${ }^{44}$ This is how he explained it in 2003:

All I ever wanted was to just have a life and play some music and study and do my little thing. But in America that's impossible, because whatever I do, it's black. When we first met [in 1984], whatever I did was white, in terms of how it was defined. But either way, as far as I'm concerned, is wrong.

I am not in African American culture, I am not in European American culture. My life has been between quadrants, I have come to see that. It would not be correct to talk of my experience as ethnocentric or idiocentric because, at every point of my life, I have not felt comfortable in the traditional parameters, as they have been defined. . . . [My] experiences have been in between all of this. (Braxton, Personal) ${ }^{45}$

What he sees as trans-idiomatic and trans-global, cultural purists of all hues still decry as transgressive. The challenge for players, for listeners, is to move beyond what Braxton refers to as "the traditional parameters, as they have been defined"; to escape from the little boxes labelled "jazz tradition" or "authentic blackness" or "European only" and all the other markers of exclusivity. Against these petty fundamentalisms Braxton sets his synaesthetic ideal of unity and openness, with its many aestheticcum-political implications, from personal affirmation to global harmony. And if the power and the beauty of his music can persuade us that the ideal is both desirable and attainable (because it works in performance), then his unique auditory perception, his vision of what he calls a sound, may help to change the way we all hear music-and see the world.

\section{Acknowledgments}

I am greatly indebted to lan Brookes, Jack Collier and David Murray for their extremely helpful comments on earlier drafts of this essay; to Hugo DeCraen and Kevin Norton for their advice and hospitality; and to the U.K. Arts and Humanities Research Council for funding the research project that made this work possible. My notes for the CD release of Composition \#94 were the starting point of the piece, so I would also like to thank Leo Feigin for commissioning those (and other) notes. I am grateful to Anthony Braxton for many reasons, not least for his kind permission to use the visual materials included here.

\section{Notes}

${ }^{1}$ Here, and in future references, I've abbreviated the Composition Notes to $C N$ followed by the appropriate volume letter: $C N-A, C N-B$, etc.

${ }^{2}$ The diagram titles, which appear only in black and white in the Composition Notes, have evolved through various phases, including the use of colour, perspective, figuration, subtitles, dialogue, landscape and photographic collage. For further discussion, see Lock (Blutopia 163-67), and DeCraen, Sinker, and Szwed.

\footnotetext{
${ }^{3}$ See Konitz.
}

${ }^{4}$ I think Braxton is referring here to a distinction he made elsewhere in the conversation between the ancient Greek (rational) and the ancient Chinese (three-dimensional) models of music. 
${ }^{5}$ Braxton has said that his titles do not resemble the "paintings" he sees in response to music, nor do they simply appear to him but have to be worked on, a process that can take longer than writing the composition. "Sometimes l'll compose a piece in a day, but the title might take two weeks" (qtd. in Lock, Forces 217).

${ }^{6} \mathrm{Cf}$. Sacks, who also thinks "it is becoming clear that there are conceptual forms of synaesthesia, too" (179n10).

${ }^{7}$ Most famously, perhaps, was Louis Armstrong, who is supposed to have replied to the question, what is jazz? with, "Lady, if you gotta ask what it is, you'll never know" (i.e., felt meaning is the meaning!). This version of the Armstrong quote, and there are many, comes from Michael Jarrett, who playfully offers seventeen variations on what Armstrong might have meant (Jarrett 7-14). We should also remember that Braxton sang in his local Baptist church as a young boy and formed his own doo wop group as a teenager, two strands of a black vocal tradition whose extensive catalogue of melismatic and meta-linguistic sounds-rasps, grunts, moans, whoops, shrieks, etc-is a further reminder that language is not always adequate for expressing "felt meaning" and that African American performers have a long tradition of communicating what may be "unsayable" by conventional means. See also Lindon Barrett's theory of the singing voice as opposed to the signing voice (Chap. 2) and Nathaniel Mackey's suggestion that "part of the genius of black music is the room it allows for a telling 'inarticulacy,"' which he ascribes to "frustration with and questioning of given articulacies, permissible ways of making sense" (252-53).

${ }^{8}$ The chief sources for my information on synaesthesia are Dann, Harrison and Cytowic (1995). Other texts relating to synaesthesia and music that I found useful include Brougher et al., Cytowic (1998), Peacock, Sacks, van Campen, Watkins and Zilczer.

${ }^{9}$ Braxton's work also provides examples of musical/textual "fluidity"; several of his compositions come with their own short stories. See, for example, Compositions \#147 and \#151, on the Braxton CD 2 Compositions (Ensemble) 1989/1991 and the single-work Braxton disc, Composition No. 165 (for 18 instrumentalists).

${ }^{10}$ It is likely that Braxton's first encounter with graphic scores came via his early interest in Stockhausen and other avant-garde composers of the 1950s and 1960s, such as Earl Browne, John Cage and lannis Xenakis. However, I argue below that the way Braxton employs his alternative notations, at least in respect of his ideas about the role of the performer(s), is more closely aligned with traditional African American creative music practice. For brief overviews of the history of graphic scores, including their use in both medieval European and non-Western music traditions, see Davies and Griffiths.

${ }^{11}$ On, respectively, Six Compositions (Quartet), 2 Compositions (Ensemble) 1989/1991, 23 Standards (Quartet) 2003, and 20 Standards (Quartet) 2003. Kandinsky's work seems an odd choice for the latter pair, since neither features any of Braxton's own compositions. The only other painter whose work he has used with more than one recording is Frederick J. Brown, with whom he went to school in Chicago (Creative Music Orchestra 1976 and Duets 1976 with Muhal Richard Abrams).

${ }^{12}$ Both Dann (54-63) and Harrison (128-29) conclude that Kandinsky was not actually a synaesthete. They reach the same conclusion about Scriabin, another popular candidate for chromaesthetic perception because, like Kandinsky, his work proposed synaesthetic ideals (Dann 71-77; Harrison 12127). Modern composers generally acknowledged to be, or to have been, genuinely synaesthetic include Michael Torke (Sacks 168-71) and Olivier Messiaen, who would experience photisms associated with sounds even when reading a score (Bernard 41-42).

${ }^{13}$ One of the chief misconceptions Dann mentions was in reference to Baudelaire's poem "Correspondances," actually a reference to Swedenborg but retrospectively misinterpreted as a celebration of synaesthesia. While Dann's arguments are persuasive, it does seem curious that the kinds of associations made by some genuine synaesthetes so closely resemble the correspondences proposed by "the ancients." For example, Dann discusses one synaesthete much documented in the scientific literature, Thomas D. Cutsforth, who "saw" (despite being blind) coloured photisms in relation to voices, musical tones, letters of the alphabet, proper names, days of the week, months of the year, numerals, dates, the cardinal directions, tastes and odours (82).

\footnotetext{
${ }^{14}$ The story's rather disappointing denouement is that Pobloff has actually hallucinated the entire episode after falling from the podium and banging his head.
} 
15 "Synthesis" is the name of Braxton's own publishing company.

${ }^{16}$ See, for example, Braxton's "Known/the Unknown/and Belief" and "Story-Mythology Progressionalism in Asia."

${ }^{17}$ Here, and in future references, l've abbreviated the Tri-Axium Writings to $T$-AW plus the relevant volume number, e.g. T-AW 1, 2, or 3.

${ }^{18}$ For his detailed explanation of this position, see Braxton ( $T$-AW $\left.3235-308\right)$. Cf. George Lewis's discussion of "Afrological" and "Eurological" musical perspectives ("Improvised Music"). Elsewhere, Braxton has stressed that he has no quarrel with notation per se, only with the "technocrats" who insist on its "correct" execution as a "choking device" that stops the lifeblood of the music, a mentality which he says is now taking over jazz (Lock, Forces 232). Cf. too Nicholas Cook's argument that, because Western musicology has long been predicated on the study of music as text, musicologists conceive of performance as simply reproduction of the score. This, he suggests, is a very inadequate model for understanding how music-making actually works (5-25).

${ }^{19}$ See, for example, his comments regarding Composition \#116, that it should "remain open to the challenges of the moment so that the invention and 'spiritual meaning' of a given participation takes precedence over any one existentially imposed criteria of 'correct.' What this means is that the notated material of Composition No. 116 can be shaped according to the particulars of its interpreters-don't worry about me please!" (CN-E 443). His various "in the tradition" recordings, including those on which he plays piano, suggest he also treats standard material in a very similar way.

${ }^{20}$ For example, the "material," "thematic," and "principle generating structures" that he used in his early quartet music. Each category proposed a different set of parameters for improvisation (Lock, "Colours" 3-4). Performances of all three can be heard on Braxton's Willisau (Quartet) 1991.

${ }^{21}$ The idea that each player should cultivate an individual sound is, of course, commonplace in jazz, but it was a particular priority in the AACM. See Lewis's "Experimental Music" (58-59). See also Olly Wilson's discussion of the African American aesthetic of heterogeneity, particularly in relation to the prizing of timbral contrast and nuance in both vocal and instrumental music (Wilson 157-71.)

${ }^{22}$ For a performance, see Kleeb. Braxton's full notes are in $C N-A(1-8)$.

${ }^{23}$ The original score included colour as part of its "visual" notation, but Braxton notes that when he revised the work in 1982, he decided to omit the colour because of the "added financial burden" it placed on reproducing the score $(C N-A)$.

${ }^{24}$ Although Braxton has participated in many performances (and some recordings) of total improvisation, his main interest is in improvisation in relation to a structural context, hence the importance he places on the role of notation. He has said that he considers structure to be "evolutionary," whereas total improvisation is "existential anarchy" (Lock, Forces 231-40). Structure is evolutionary because it enables musical information, encoded within structural principles, to be passed down from generation to generation: "the understanding being that given structures will make certain things happen. That's what structure is ..." (232).

${ }^{25}$ A solo piano version of Composition \#10 can be heard on Kleeb. For two arrangements for quintet (by Art Lange), see Gregorio et al. The players are Guillermo Gregorio, Carrie Biolo, Michael Cameron, Gene Coleman and Jim O'Rourke. Braxton's full notes are in CN-A (173-83).

${ }^{26}$ He suggests that a performance should "reveal [the score's] actual visual material" to the listener, and likens the performer to "a painter who translates visual images into a concrete entity" (CN-A 173). As with Composition \#1, he had later to remove colour from the score in order to cut costs.

${ }^{27}$ These factors also determine the directions in which the musicians face at different points during a concert performance of Composition \#82. (This work, for four orchestras, is about moving sound through and around the performance space, so the musicians are seated on tiers of swivel chairs that encircle the audience.) Braxton's notes on \#82 are in $C N-D$ (279-309). A partial performance can be heard on Braxton's For Four Orchestras, which has yet to be issued on CD. For more on \#82, see Lange (12230). 
${ }^{28}$ For the complete colour code to Composition \#76, see Lock (Forces 222). Braxton did not specify which astrological tradition he had drawn on here. His notes on \#76 are in $C N-D$ (136-54).

Performances can be heard on Braxton's For Trio, which comprises two versions of \#76 (one by Braxton, Douglas Ewart and Henry Threadgill, the other by Braxton, Joseph Jarman and Roscoe Mitchell). The original vinyl recording has not yet been reissued on CD. For further discussion of \#76, including an example of Braxton introducing perspective into the notation (to give it a three-dimensional appearance), see Heffley (317-22).

${ }^{29}$ Braxton's notes are in $C N-D(247-58(\# 78))$ and (332-38 (\#84)). Neither piece has appeared on record.

${ }^{30}$ A performance can be heard on Braxton's For Two Pianos. The players are Ursula Oppens and Frederic Rzewski. Braxton's notes are in $C N-E(1-25)$. The quote about alerting the spirit is on page 3.

${ }^{31}$ Braxton's full notes are in $C N-D$ (457-71). A live performance can be heard on Braxton's Composition No. 94 for Three Instrumentalists (1980). The players are Braxton, Ray Anderson and James Emery.

${ }^{32}$ My italics, although in the original text Braxton has underlined this whole sentence.

${ }^{33}$ As well as the shapes, symbols and other notations here, Braxton gives the musicians further options to affirm their personalities in a given performance of Composition \#94. These include omitting pages of the score, repeating pages of the score, changing the order of the pages and playing the pages in reverse order. See also Heffley (323-26).

${ }^{34}$ Braxton's full notes are in $C N-E$ (77-88). In addition to the cloud-like shapes, he uses other unusual notations here too, including "collage mobiles" and symbolic notation. A performance can be heard on Anthony Braxton, Composition 98. The players are Braxton, Ray Anderson, Marilyn Crispell and Hugh Ragin. For an earlier instance of Braxton asserting that "there is no conflict between notation and improvised music," see Lake, 19-23.

${ }^{35}$ I use the term non-finished as opposed to "unfinished" to emphasize that the leaving of space within the work's structure is intentional.

${ }^{36}$ Cf. composer Thomas Adès's rather curious alarm at the thought of incorporating spaces for improvisation in his work. To do so would, he argues, mean that 'in 70 or 80 years' time there'll be this very weird situation where you'll have these scores with holes in them, and the people won't be there to fill the holes in" (qtd. in Hamilton 171.) Braxton's contrasting belief is that, by incorporating improvisation into the musical structure, "the holes" allow a score to remain open-i.e. relevant and usable-to many different players (and audiences) at many different times in many different situations. In other words, he sees the score as providing co-ordinates to initiate performance, whereas Adès regards it as a fixed text; or, as Hamilton puts it, Adès is "evidently more interested in product than process" (171).

${ }^{37}$ For further analysis of this topic in reference to Braxton's work, see Richard Barrett and Peter Niklas Wilson. For a broader discussion of "the Creolization of composition" and new music hybridity, with particular reference to the AACM, see Lewis ("Experimental Music" 71-91).

${ }^{38}$ Braxton's full notes are in $C N-E$ (26-60). Very different versions of Composition \#96 can be heard on Braxton's Composition No. 96 and 4 (Ensemble) Compositions-1992.

${ }^{39}$ For Braxton's own explanation of pulse tracks, see Lock (Forces 195-206). See also Heffley (54-56).

${ }^{40}$ Braxton's full notes are in $C N-E(311-18)$.

${ }^{41}$ In Braxton's quartet performances of the early 1980s, the pulse track Composition \#108B was usually played together with Composition \#110A. The first recording of these pieces, designated as "Composition 110A (+108B)," can be heard on Braxton's Six Compositions (Quartet) 1984, where the performers are Braxton, Marilyn Crispell, Gerry Hemingway and John Lindberg. A live version of the same compositional pairing (plus further options) by the same group, except with Mark Dresser on bass in place of John Lindberg, can be heard on Braxton's Quartet (Birmingham) 1985. On the track listing for the original issue of the latter disc, the first two composition numbers (but not the diagram titles) have 
been accidentally transposed, so contrary to the track listing, "Composition $110(+96+108 \mathrm{~B})$ " is actually the second main work played. On the later reissue, the composition numbers have been listed in the correct order, but now the diagram titles have been erroneously transposed.

${ }^{42}$ I have taken the liberty of slightly amending the punctuation from my original transcription of the interview.

${ }^{43}$ Braxton is by no means the first person to argue for the political benefits of a "trans-idiomatic" music: for instance, the Baroque composer Georg Muffat (1653-1704) hoped that his blending of French, German and Italian styles might help to reunite a war-torn Europe (Early).

${ }^{44}$ These Others might include, for example, Indian, Chinese and Japanese influences, all referenced in the Composition Notes; or, as in the case of Composition \#76, work specifically designed so that the performer "takes on a different role from that of the classical or improvising traditions" ( $C N-D 139$, emphasis added). The dualism l've posited in this essay, between European (American) and African (American) is, of course, a simplification, although one which I thought might be helpful in illuminating the specific themes I was concerned with here. It would become an oversimplification if applied to a discussion of Braxton's work as a whole. Cf. too Mark Sinker's provocative observation that "Braxton's worldview seems remarkable in that it's open, equally, [. . .] to everything and its opposite" (230). Braxton himself attributes this capability to his being a Gemini: as he told me (another Gemini), "Anything we can talk about we can also talk about and prove its opposite-as a Gemini you must be aware of that!" (Lock, Forces 205).

${ }^{45}$ Cf. his 1994 critique of “the concepts which said, you can't listen to Schoenberg because it's not relevant to your experience. Or, you can't listen to George Clinton because you can't like Schoenberg and George Clinton [... .] And l'm saying, wait a minute, this is part of the baggage of unhappiness related to this millennium. The next millennium and the generation coming up now-why burden them, why burden anyone, with these concepts?" (qtd. in Lock, "Highway" 249).

\section{Works Cited}

Barrett, Lindon. Blackness and Value. Cambridge: Cambridge UP, 1999.

Barrett, Richard. "Who Wants to Be a 'Composer' Anyway?" Mixtery: A Festschrift for Anthony Braxton. Ed. Graham Lock. Exeter: 1995. 174-77.

Bernard, Jonathan W. "Messiaen's Synaesthesia: The Correspondence between Colour and Sound Structure in His Music." Music Perception 4.1 (Fall 1986): 41-42.

Braxton, Anthony. 2 Compositions (Ensemble) 1989/1991. hat ART, 1992.

---. 4 (Ensemble) Compositions-1992. Black Saint, 1993.

---. 20 Standards (Quartet) 2003. Leo, 2005.

---. 23 Standards (Quartet) 2003. Leo, 2004.

---. Composition 94 for Three Instrumentalists (1980). Golden Years, 1999.

---. Composition No.96. Leo, 1993.

---. Composition 98. hat ART, 1990.

---. Composition No. 165 (for 18 instrumentalists). New Albion, 1992.

---. Composition Notes. 5 vols. Synthesis Music, 1988.

---. Creative Music Orchestra 1976. Arista, 1976. 
---. Duets 1976 with Muhal Richard Abrams. Arista, 1976.

---. For Four Orchestras [aka Composition 82]. Arista, 1978.

---. For Trio [aka Composition 76]. Arista, 1978.

---. For Two Pianos [aka Composition 95]. Arista, 1982.

---. "Known/the Unknown/and Belief." http://www.wesleyan.edu/music/braxton/papers/historyscience.html.

---. Personal interview with Graham Lock. Brussels. 23 February 2003.

---. Quartet (Birmingham) 1985. Leo, 1991.

---. Six Compositions: Quartet. Antilles, 1982.

---. Six Compositions (Quartet) 1984. Black Saint, 1985.

---. "Story-Mythology Progressionalism in Asia." http://www.wesleyan.edu/music/braxton/papers/storymythology.html.

---. Tri-Axium Writings. 3 vols. Synthesis Music, 1985.

---. Willisau (Quartet) 1991. hat ART, 1992.

Braxton, Anthony and Matt Bauder. 2+2 Compositions. 482 Music, 2005.

Brougher, Kerry, Jeremy Strick, Ari Wiseman and Judith Zilczer. Visual Music: Synaesthesia in Art and Music since 1900. London: Thames \& Hudson, 2005.

Cook, Nicholas. "Making Music Together, or Improvisation and Its Others." The Source 1 (2004): 5-25.

Cytowic, Richard E. The Man Who Tasted Shapes. Cambridge, MA: MIT Press, 1998.

---. "Synaesthesia: Phenomenology and Neuropsychology. A Review of Current Knowledge." Psyche: An Interdisciplinary Journal of Research on Consciousness 2.10 (July 1995). http://psyche.cs.monash.edu.au/v2/psyche-2-10-cytowic.html.

Dann, Kevin T. Bright Colors Falsely Seen: Synaesthesia and the Search for Transcendental Knowledge. New Haven, CT: Yale UP, 1998.

DeCraen, Hugo. "Braxton and Kandinsky: Symbolists of the Spiritual." Mixtery: A Festschrift for Anthony Braxton. Ed. Graham Lock. Exeter: 1995. 212-24.

Davies, Hugh. "Musical Notation-Old and New." Eye Music: The Graphic Art of New Musical Notation. Exhibition Catalogue. London: Arts Council of Great Britain, 1986. 12-28.

Düchting, Hajo. Wassily Kandinsky, 1866-1944: A Revolution in Painting. Köln: Taschen, 2000.

Eye Music: The Graphic Art of New Musical Notation. Exhibition catalogue. London: Arts Council of Great Britain, 1986.

The Early Music Show. BBC Radio 3. 13 Jan. 2008.

Gregorio, Guillermo, et al. Anthony Braxton: Compositions No. 10 \& No. 16 (+101). hat ART, 1998. 
Griffiths, Paul. "Sound-Code_Image." Eye Music: The Graphic Art of New Musical Notation. Exhibition catalogue. London: Arts Council of Great Britain, 1986. 5-11.

Gundaker, Grey. Signs of Diaspora, Diaspora of Signs: Literacies, Creolization, and Vernacular Practice in African America. New York: Oxford UP, 1998.

Hamilton, Andy. "The Art of Improvisation and the Aesthetics of Imperfection." British Journal of Aesthetics 40.1 (January 2000): 168-85.

Harrison, John. Synaesthesia: The Strangest Thing. Oxford: Oxford UP, 2001.

Heffley, Mike. The Music of Anthony Braxton. Westport, CT: Greenwood Press, 1996.

Huneker, James. "The Disenchanted Symphony." Melomaniacs. New York: Scribner's, 1902.

Jarrett, Michael. Drifting on a Reed: Jazz as a Model for Writing. Albany: SUNY Press, 1999.

Kleeb, Hildegard. Anthony Braxton: Piano Music (Notated) 1968-1988. hat ART, 1996.

Konitz, Lee. Lee Konitz Meets Jimmy Giuffre. 1959. Verve, 1996.

Lake, Steve. “There's God on a Chessboard.” Musics 13 (August 1977): 19-23.

Lange, Art. "Implications of a Creative Orchestra, 1972-1978." Mixtery: A Festschrift for Anthony Braxton. Ed. Graham Lock. Exeter: 1995. 122-30.

Lewis, George. "Experimental Music in Black and White: The AACM in New York, 1970-1985." Uptown Conversation: The New Jazz Studies. Eds. Robert O'Meally, Brett Hayes Edwards, and Farah Jasmine Griffin. New York: Columbia UP, 2004. 50-101.

---. "Improvised Music after 1950: Afrological and Eurological Perspectives." Black Music Research Journal 16.1 (Spring 1996): 91-122.

Lock, Graham. Blutopia: Visions of the Future and Revisions of the Past in the Work of Sun Ra, Duke Ellington, and Anthony Braxton. Durham, NC: Duke UP, 1999.

---. "Colours of the Spiritway: 25 Years of Anthony Braxton's Compositions for the Creative Ensemble: Stories \& Histories." Notes to the studio-CDs booklet for Willisau (Quartet) 1991. By Anthony Braxton. hat ART, 1992.

---. Forces in Motion: Anthony Braxton and the Meta-reality of Creative Music. London: Quartet Books, 1988.

---. "The Hearing Eye, the Seeing Ear." CD-booklet notes. Composition No. 94 for Three Instrumentalists (1980). By Anthony Braxton. Golden Years, 1999.

---. "A Highway to the Cosmics." Mixtery: A Festschrift for Anthony Braxton. Ed. Graham Lock. Exeter: Stride, 1995. 246-49.

Mackey, Nathaniel. Discrepant Engagement: Dissonance, Cross-Culturality, and Experimental Writing. 1993. Tuscaloosa: University of Alabama Press, 2000.

Palmer, John, ed. In Praise of Music. London: Frederick Muller, 1951.

Peacock, Kenneth. "Instruments to Perform Color-Music." Leonardo 21.4 (1988): 397-406. 
Sacks, Oliver. Musicophilia: Tales of Music and the Brain. London: Picador, 2007.

Shaw-Miller, Simon. Visible Deeds of Music: Art and Music from Wagner to Cage. New Haven: Yale UP, 2002.

Sinker, Mark. Untitled essay. Mixtery: A Festschrift for Anthony Braxton. Ed. Graham Lock. Exeter: 1995. 226-37.

Stockhausen, Karlheinz. Towards a Cosmic Music. Shaftesbury: Element Books, 1989.

Szwed, John F. "The Local and the Express: Anthony Braxton's Title-Drawings." Mixtery: A Festschrift for Anthony Braxton. Ed. Graham Lock. Exeter: 1995. 207-12.

Taylor, Arthur. Notes and Tones: Musician-to-Musician Interviews. 1982. London: Quartet, 1983.

van Campen, Chretien. The Hidden Sense: Synaesthesia in Art and Science. Cambridge, MA: MIT Press, 2008.

Watkins, Glen. Soundings: Music in the Twentieth Century. New York: Schirmer, 1988.

Wilmoth, Charlie. Untitled CD-booklet notes. 2+2 Compositions. By Anthony Braxton and Matt Bauder. 482 Music, 2005.

Wilson, Olly. "The Heterogeneous Sound Ideal in African American Music." Signifyin(g), Sanctifyin', \& Slam Dunking: A Reader in African American Expressive Culture. Ed. Gena Dagel Caponi. Amherst: $U$ of Massachusetts $P, 1999.157-71$.

Wilson, Peter Niklas. "Firmly Planted in Mid-Air: Notes on the Syntax and Aesthetics of Anthony Braxton's 'Composition 151' (1991)." Mixtery: A Festschrift for Anthony Braxton. Ed. Graham Lock. Exeter: 1995. 133-44.

Young, Al. Kinds of Blue. San Francisco: Donald S. Ellis, 1984.

Zilczer, Judith. "Synaesthesia and Popular Culture: Arthur Dove, George Gershwin, and the 'Rhapsody in Blue."' Art Journal 44.4 (Winter 1984): 361-66. 